Short Communication

\title{
PATRIOT: A phase I study to assess the tolerability, safety and biological effects of a specific ataxia telangiectasia and Rad3-related (ATR) inhibitor (AZD6738) as a single agent and in combination with palliative radiation therapy in patients with solid tumours
}

\author{
M.T. Dillon ${ }^{\mathrm{a}, \mathrm{b}, *}$, Z. Boylan ${ }^{\mathrm{c}}$, D. Smith ${ }^{\mathrm{b}}$, J. Guevara ${ }^{\mathrm{b}}$, K. Mohammed ${ }^{\mathrm{b}}$, C. Peckitt ${ }^{\mathrm{b}}$, M. Saunders $^{\mathrm{d}}$, \\ U. Banerji ${ }^{\mathrm{b}}$, G. Clack $^{\mathrm{h}}$, S.A. Smith ${ }^{\mathrm{e}}$, J.F. Spicer ${ }^{\mathrm{f}}$, M.D. Forster ${ }^{\mathrm{g}, 1}$, K.J. Harrington ${ }^{\mathrm{a}, \mathrm{b}, 1}$ \\ a The Institute of Cancer Research, London, UK \\ ${ }^{\mathrm{b}}$ The Royal Marsden NHS Foundation Trust, London, UK \\ ${ }^{\mathrm{c}}$ Cancer Research UK, London, UK \\ ${ }^{\mathrm{d}}$ The Christie NHS Foundation Trust, UK \\ e AstraZeneca, Cambridge, UK \\ ${ }^{\mathrm{f}}$ Kings College London, UK \\ ${ }^{\mathrm{g}}$ University College London Hospitals NHS Foundation Trust and UCL Cancer Centre, London UK \\ ${ }^{\mathrm{h}}$ Department of Oncology and Metabolism, University of Sheffield Medical School, Beech Hill Road, SHEFFIELD S10 2RX, UK
}

\section{A R T I C L E I N F O}

\section{Article history:}

Received 23 May 2018

Accepted 6 June 2018

Available online 8 June 2018

Keywords:

Phase I

Radiosensitization

ATR inhibition

DNA damage response

Clinical trial

\begin{abstract}
A B S T R A C T
PATRIOT is a phase I study of the ATR inhibitor, AZD6738, as monotherapy, and in combination with palliative radiotherapy. Here, we describe the protocol for this study, which opened in 2014 and is currently recruiting and comprises dose escalation of both drug and radiotherapy, and expansion cohorts.

(c) 2018 The Authors. Published by Elsevier B.V. on behalf of European Society for Radiotherapy and Oncology. This is an open access article under the CC BY-NC-ND license (http://creativecommons.org/
\end{abstract} licenses/by-nc-nd/4.0/).

\section{Background}

Radiotherapy is used in the treatment of approximately $40 \%$ of cancer patients [1]. It is used as a primary treatment in combination with chemotherapy in locally advanced cancers of the head and neck, lung, oesophagus, rectum, anus and as part of multimodality treatment in numerous other cancers. Standard-of-care chemoradiation has been shown to be superior to radiation alone in most cancers where it is used for primary treatment, at the expense of increased normal tissue toxicity. In spite of this, tumour control rates, and consequent survival, remain inadequate in a number of clinical settings.

Many strategies have been investigated over recent decades to attempt to improve outcomes with radiotherapy, including altered fractionation, dose-escalation with the use of advanced radiotherapy techniques, hypoxia modification and combination with tar-

\footnotetext{
* Corresponding author at: The Institute of Cancer Research, London, UK.

E-mail address: magnus.dillon@icr.ac.uk (M.T. Dillon).

1 These Authors contributed equally to this work.
}

geted therapies and immunotherapy [2]. These have met with limited degrees of success.

Targeting the G2 cell cycle checkpoint is an attractive option for selective sensitisation of tumour cells to radiation [3]. There are multiple lines of preclinical data demonstrating that inhibiting this checkpoint through kinase inhibition of ATR and CHK1 will sensitise to radiation therapy, by increasing mitotic cell death and reducing DNA repair [4-9]. There are currently three ATR inhibitors in early clinical development, including AZD6738, an orally bioavailable inhibitor of the ATR kinase [10]. ATR is critical in the cellular response to DNA replication stress, the levels of which are elevated in many cancers as a result of oncogene activation, endogenous and exogenous DNA damage [11], and targeting this may be a novel therapeutic strategy.

Traditionally, combination of novel agents with radiation therapy has not taken place until monotherapy studies at phase I or later have completed, with some evidence of monotherapy effect. This study is notable for introducing radiation combination studies early in the clinical development of AZD6738. 
Here, we describe the clinical trial protocol of the PATRIOT study, which combines AZD6738 monotherapy dose-escalation and dose-expansion components with a combination phase I component with palliative radiotherapy.

\section{Methods and study design}

PATRIOT is co-sponsored by the Royal Marsden and The Institute of Cancer Research. The study is jointly funded by Cancer Research UK, AstraZeneca and the Experimental Cancer Medicines Network as part of the Combinations Alliance collaborative agreement. The study has been approved by the National Research Ethics Committee (14/LO/0465). It is registered on the clinicaltrials.gov (NCT02223923) and EudraCT (2013-003994-84) databases.

It is a multi-centre, open-label, non-randomised phase I study of AZD6738 in advanced solid tumours with three parts: monotherapy dose-escalation (part A), monotherapy doseexpansion at maximum tolerated dose (MTD) (part B), and doseescalation in combination with palliative radiotherapy (part C). This design was chosen in order to gain information about monotherapy toxicity prior to combination with radiation, to investigate dosing schedules which would be amenable to combination with radiation combination, and improve monotherapy tolerability, and to gain further information about markers of response to AZD6738.

Parts $A$ and $C$ of the study are $3+3$ dose-escalation designs (Figs. 1, 2). Part A has single-patient cohorts at lower dose levels, changing to $3+3$ at the first G2 toxicity. Part $C$ initially escalates drug dose, followed by escalation of radiation dose. It allows dose escalation of AZD6738 with $20 \mathrm{~Gy}$ in 10 fractions of radiotherapy, starting at least 2 dose-levels below the currently tolerated dose of AZD6738. At the MTD, or a dose lower than MTD as determined by the safety review committee, the radiation dose will be escalated to $30 \mathrm{~Gy}$ in 15 fractions, with 10 fractions sensitised, further cohorts will sensitise 15 fractions and expansion cohorts will add maintenance AZD6738 until disease progression (Fig. 2).

Part C of the study will run 2 parallel tracks, stratifying by site of irradiation into disease above and below the diaphragm, in order to provide more meaningful information on specific toxicities. These two tracks will be treated independently, and may result in different recommended doses to proceed for each site of irradiation.

Total number of patients for parts $A$ and $C$ will depend upon the toxicities encountered. Part B will treat a maximum of 50 patients.

\section{Selected inclusion and exclusion criteria}

Inclusion criteria

1. Histologically or cytologically documented solid tumour without further standard therapy options.

2. Part B only: documented disease progression prior to study entry, tumour site amenable to fresh biopsy.

3. Part C only: disease causing or likely to cause symptoms within a short period of time such that palliative radiotherapy is indicated or justified.

4. Evidence of measurable or evaluable disease by RECIST 1.1.

5. ECOG performance status 0-1 (part A); 0-2 (parts B and C).

6. Life expectancy of at least 3 months.

7. Adequate and stable haematological, hepatic and renal function.

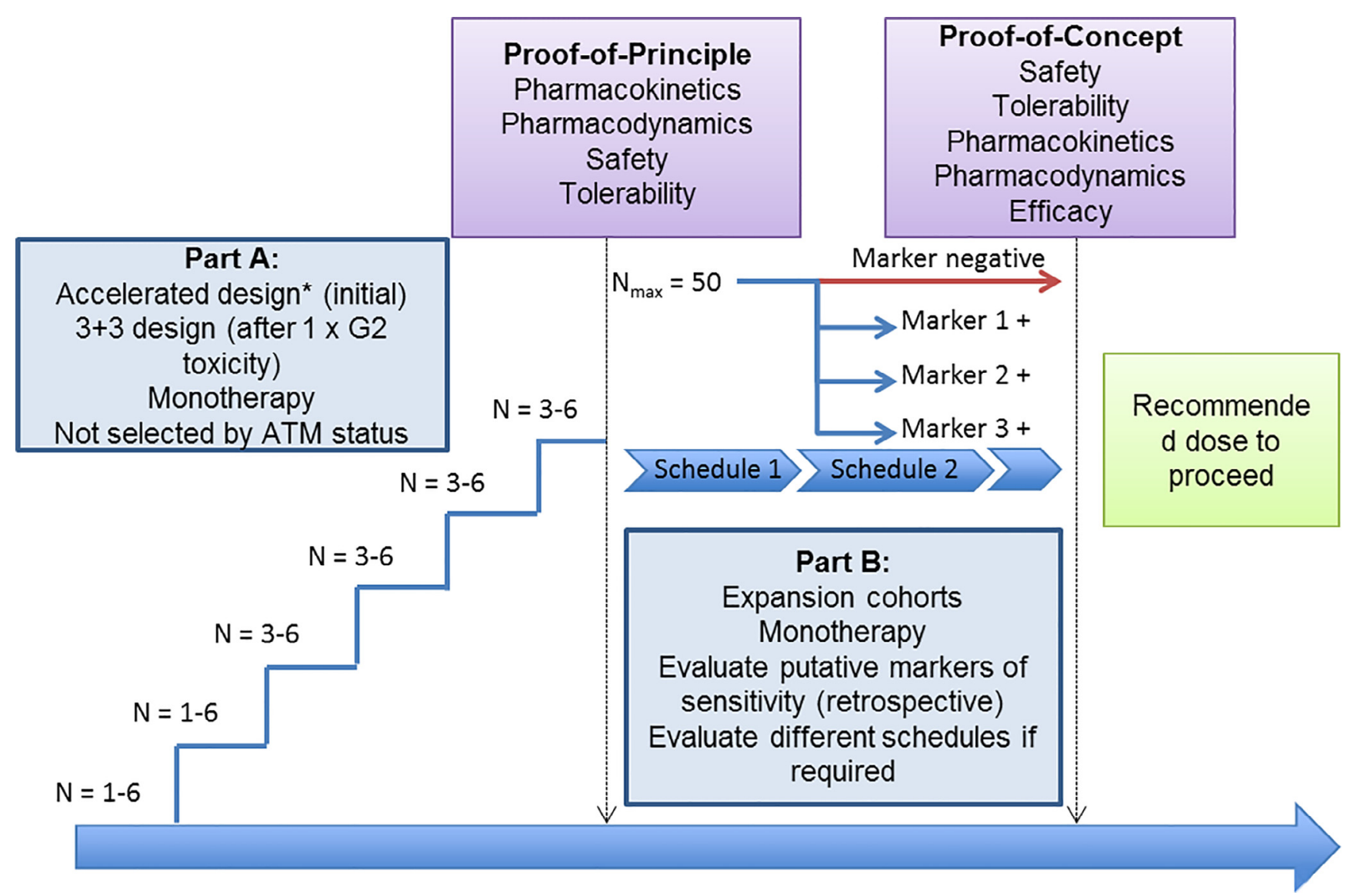

Fig. 1. study design for parts $A$ and $B$. 


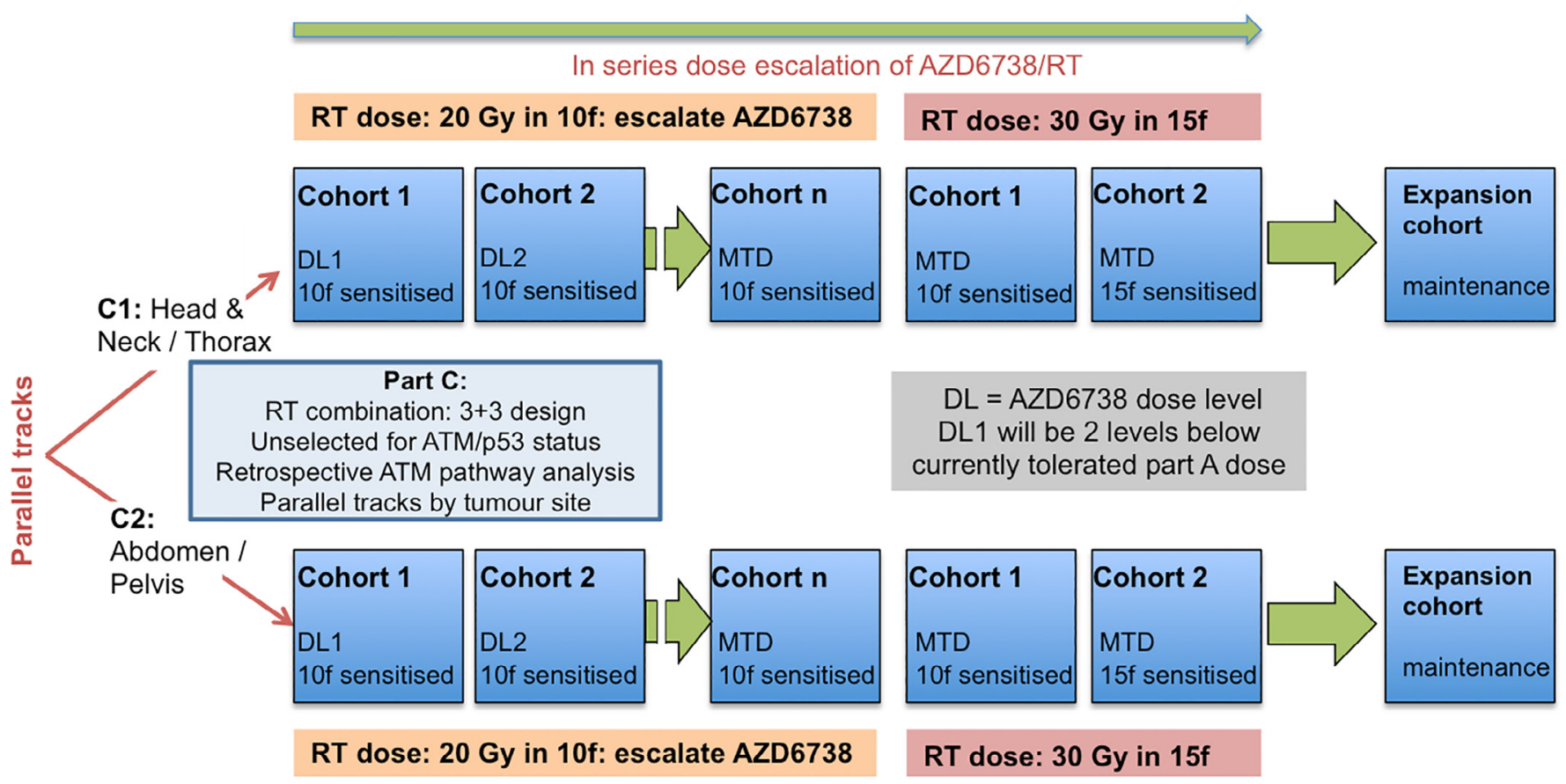

Fig. 2. study design for part C.

8. Not pregnant, using adequate contraception.

9. Willing and able to comply with scheduled visits, tissue sampling, treatment plan, and laboratory tests.

10. Able to swallow, absorb and retain oral medication.

\section{Exclusion criteria}

1. Part C only: prior radiotherapy to the treatment site.

2. Concomitant anti-cancer therapy or investigational medical products) (long-term hormonal therapy permitted in part $\mathrm{C}$ ).

3. Receiving, or having received, concomitant medications, herbal supplements and/or foods that significantly modulate CYP3A4.

4. Pregnant or breast-feeding women.

5. Clinically significant cardiac disease.

6. Known HIV positive or active hepatitis B or $\mathrm{C}$ infection.

7. Uncontrolled active infection.

8. Symptomatic and progressive or steroid-requiring brain metastases or leptomeningeal disease involvement.

9. Uncontrolled hypertension.

10. Relative hypotension or clinically relevant orthostatic hypotension.

11. Haematuria: +++ on microscopy or dipstick.

\section{Objectives and endpoints}

The primary objective of the study is to determine the feasibility and safety of administration of AZD6738 as a single-agent and in combination with different schedules of radiotherapy. Toxicity will be recorded using CTCAE 4.03 criteria, and definitions of dose-limiting toxicity are given in Table 1.

The secondary objectives are to guide dose and schedule selection for subsequent later-phase studies of AZD6738 as a singleagent or with palliative or radical radiotherapy, to perform pharmacokinetic analysis of plasma drug levels after single and multiple doses, and to assess preliminary anti-tumour activity (by RECIST response) of AZD6738 as a single-agent and in combination with palliative radiotherapy.
Exploratory objectives of the study are to conduct pharmacodynamic studies on tumour and normal tissue, and explore the value of putative predictive biomarkers for response to AZD6378.

\section{Study treatments}

Patients will take AZD6738 tablets by mouth, twice daily. Proposed dose escalation schema is shown in Table 2. Part A of the study has continuous dosing in 28-day cycles, part B allows intermittent schedules. Tumour response assessments will take place every 2 cycles ( 8 weeks). During part C, participants will start taking AZD6738 three to seven days before radiotherapy starts, then continuously through radiation, finishing two days after the final sensitised fraction. Response assessments will take place at 4 and 8 weeks after the end of radiotherapy.

\section{Duration of study}

During the monotherapy parts of the study, participants will continue taking AZD6738 until disease progression, unacceptable toxicity or withdrawal of consent. During radiation, participants will take a defined duration of AZD6738 around the course of radiotherapy, unless in expansion cohorts, where they will continue maintenance AZD6738 until disease progression. Participants will be followed up until acute toxicity resolves to baseline or $\leq$ grade 1 . Participants in part $\mathrm{C}$ will be followed up for late toxicity at three-monthly intervals for one year. Where physical attendance is not possible, telephone contact will be made with referring oncologist or general practitioner to establish whether there is significant late toxicity. Overall survival will not be assessed.

\section{Data analysis}

Data analysis will be descriptive, with analysis taking place at every dose-level to inform dose-escalation decisions. Toxicity will be graded according to CTCAE v4.03 and dose-limiting toxicities are defined in Table 1 . Late toxicity after three months from 
Table 1

definition of dose-limiting toxicity.

\begin{tabular}{|c|c|c|c|}
\hline Haematological & $\begin{array}{l}\text { Thrombocytopenia } \\
\text { - G3 with bleeding } \\
\text { - G4 }\end{array}$ & $\begin{array}{l}\text { Neutropenia } \\
\text { - Lasting }>7 \text { days in absence of growth } \\
\text { factor support } \\
\text { - Any duration accompanied by fever } \\
\geq 38.5^{\circ} \mathrm{C} \text { and/or systemic infection }\end{array}$ & Any other $\geq$ G4 haematological toxicity \\
\hline Gastrointestinal & $\begin{array}{l}\text { ALT or AST }>5 \text { times ULN; ALP }>5 \text { times ULN } \\
\text { with elevated gamma-GT }\end{array}$ & $\begin{array}{l}\text { ALT or AST }>3 \text { times ULN (or ALP }>3 \text { times } \\
\text { ULN with elevated gamma-GT) with the } \\
\text { appearance of symptoms associated with } \\
\text { a clinical diagnosis of hepatitis including } \\
\text { right upper quadrant pain or tenderness, } \\
\text { fever, rash or eosinophilia }(>5 \%)\end{array}$ & $\begin{array}{l}\text { [ALT or AST }>3 \text { times ULN] and [total } \\
\text { bilirubin }>2 \text { times ULN] or INR }>1.5 \times \text { ULN } \\
\text { (unless patient receiving warfarin) (or } \\
\text { other evidence of impaired liver synthetic } \\
\text { function) }\end{array}$ \\
\hline \multirow[t]{2}{*}{ Cardiovascular } & Hypotension & Orthostatic hypotension & Prolongation of QTC \\
\hline & $\begin{array}{l}\text { Clinically significant hypotension defined as an } \\
\text { asymptomatic fall in systolic blood pressure } \\
\text { more than } 20 \mathrm{mmHg} \text { to below } 70 \mathrm{mmHg} \\
\text { persisting for at least } 10 \mathrm{~min}\end{array}$ & $\begin{array}{l}\text { Symptomatic orthostatic fall in systolic } \\
\text { blood pressure of more than } 20 \mathrm{mmHg} \\
\text { compared to resting supine blood } \\
\text { pressure }\end{array}$ & $\begin{array}{l}>0.5 \mathrm{~s} \text { (using an appropriate correction } \\
\text { QTcB (Bazzett) or QTcF (Fridericia)) }\end{array}$ \\
\hline Dose delay & $\begin{array}{l}\text { Any dose in cycle } 1 \text {, or the start of cycle } 2 \text {, } \\
\text { delayed by more than } 7 \text { days due to toxicity }\end{array}$ & $\begin{array}{l}\text { Patient unable to complete cycle } 1 \text { at the } \\
\text { planned dose due to toxicity (parts A and } \\
\text { B only) }\end{array}$ & \\
\hline Any other toxicity & $\begin{array}{l}\text { Any other toxicity that is greater than baseline, } \\
\text { is clinically significant and/or unacceptable, } \\
\text { does not respond to supportive care }\end{array}$ & $\begin{array}{l}\text { Any other toxicity that results in a } \\
\text { disruption of dosing schedule of more } \\
\text { than } 14 \text { days }\end{array}$ & $\begin{array}{l}\text { Any other toxicity considered to be dose- } \\
\text { limiting by the investigators }\end{array}$ \\
\hline $\begin{array}{l}\text { Part C (radiotherapy } \\
\text { combination) only }\end{array}$ & $\begin{array}{l}\text { G3/4 radiation-induced skin or mucosal toxicity } \\
\text { judged by the investigator to be significantly in } \\
\text { excess of expected radiation reaction }\end{array}$ & $\begin{array}{l}\text { Inability to tolerate one week of } \\
\text { combination therapy due to toxicity }\end{array}$ & \\
\hline
\end{tabular}

Table 2

proposed dose escalation of AZD6738, "these cohorts are recommended intermediate dose-levels for de-escalation.

\begin{tabular}{ll}
\hline Cohort & Dose of AZD6738 \\
\hline 1 & $20 \mathrm{mg} \mathrm{BD}$ \\
2 & $40 \mathrm{mg} \mathrm{BD}$ \\
$2 \mathrm{a}^{*}$ & $60 \mathrm{mg} \mathrm{BD}$ \\
3 & $80 \mathrm{mg} \mathrm{BD}$ \\
$3 \mathrm{a}^{*}$ & $120 \mathrm{mg} \mathrm{BD}$ \\
4 & $160 \mathrm{mg} \mathrm{BD}$ \\
$4 \mathrm{a}^{*}$ & $200 \mathrm{mg} \mathrm{BD}$ \\
5 & $240 \mathrm{mg} \mathrm{BD}$ \\
\hline
\end{tabular}

completion of treatment will be graded using LENT-SOMA scoring. Dose-escalation decisions will be made using a dose-limiting toxicity (DLT) window of the first cycle (28 days) treatment for part A, and until 2 weeks after the end of radiotherapy for part C. Significant late toxicity will be taken into account when making doseescalation decisions for part $\mathrm{C}$, although this has not been formally incorporated into the study design. Dose escalation decisions are through a safety review committee, chaired by an independent external clinical oncologist, with a senior ECMC clinician who is not an investigator also on the committee.

\section{Discussion}

PATRIOT is notable for integrating a radiation combination study early in the clinical development of a drug. Drugs enhancing radiation response are an area for potential significant gains in cure rates with radical treatment, although cautious study design is essential given the risk of long-term radiation toxicity $[12,13]$. PATRIOT attempts to gain more meaningful toxicity data from a study treating a wide range of patients by stratifying by site of irradiation. The study will escalate radiation dose from $20 \mathrm{~Gy}$ to $30 \mathrm{~Gy}$, in $2 \mathrm{~Gy}$ fractions, to investigate the effect in a fractionation schedule relevant to radical treatment.

Multiple biomarkers have been proposed for response to ATR inhibitors as monotherapy or in combination in preclinical studies, mainly loss of components of the DNA damage response or high levels of replication stress [14]. Translational studies using material from patients in this study will focus on potential predictive biomarkers to ATR inhibition. We hypothesise that tumours with a defective DNA damage response will be more likely to respond to ATR inhibition, either with or without radiotherapy. Patients entering part $B$ of the study will have fresh biopsy material analysed for a number of DDR components, using DNA sequencing and immunohistochemistry, and other participants will have archival material analysed, if it is available.

If the combination is well tolerated, we aim to proceed to a randomised study comparing standard-of-care radiotherapy or chemoradiotherapy to the addition of AZD6738 in a patient population treated with radical intent.

\section{Conflict of interest}

The authors declare no conflict of interest.

\section{Acknowledgements}

PATRIOT is co-sponsored by The Royal Marsden and The Institute of Cancer Research, funded by the ECMC Combinations Alliance and supported by supply of free drug and distribution costs from AstraZeneca. MTD is a CRUK clinical research fellow, and received funding from The Rosetrees Trust. The authors acknowledge financial support from the United Kingdom (UK) Department of Health via the National Institute for Health Research (NIHR) Biomedical Research Centre (BRC) award to the RM/ICR Biomedical Research Centre, to Guy's \& St Thomas' NHS Foundation Trust in partnership with King's College London and King's College Hospital NHS Foundation trust and NIHR CRF, and to UCL Hospitals NHS Foundation Trust and University College London. CRUKD/14/007.

\section{References}

[1] Round CE et al. Radiotherapy demand and activity in England 2006-2020. Clin Oncol 2013;25(9):522-30.

[2] Dillon MT, Harrington KJ. Human papillomavirus-negative pharyngeal cancer. J Clin Oncol 2015.

[3] Dillon MT, Good JS, Harrington KJ. Selective targeting of the G2/M cell cycle checkpoint to improve the therapeutic index of radiotherapy. Clin Oncol (R Coll Radiol) 2014;26(5):257-65 
[4] Dillon MT et al. Radiosensitization by the ATR inhibitor AZD6738 through generation of acentric micronuclei. Mol Cancer Ther 2017;16(1):25-34.

[5] Prevo $R$ et al. The novel ATR inhibitor VE-821 increases sensitivity of pancreatic cancer cells to radiation and chemotherapy. Cancer Biol Ther 2012;13(11):1072-81.

[6] Pires IM et al. Targeting radiation-resistant hypoxic tumour cells through ATR inhibition. Br J Cancer 2012;107(2):291-9.

[7] Borst GR et al. Targeted radiosensitization by the Chk1 inhibitor SAR-020106. Int J Radiat Oncol Biol Phys 2013;85(4):1110-8.

[8] Engelke CG et al. Sensitization of pancreatic cancer to chemoradiation by the Chk1 inhibitor MK8776. Clin Cancer Res 2013.

[9] Morgan MA et al. Mechanism of radiosensitization by the Chk1/2 inhibitor AZD7762 involves abrogation of the G2 checkpoint and inhibition of homologous recombinational DNA repair. Cancer Res 2010;70(12):4972-81.
[10] Jones CD et al. Abstract 2348: discovery of AZD6738, a potent and selective inhibitor with the potential to test the clinical efficacy of ATR kinase inhibition in cancer patients. Cancer Res. 2013;73(8 Suppl):2348.

[11] Zeman MK, Cimprich KA. Causes and consequences of replication stress. Nat Cell Biol 2014;16(1):2-9.

[12] Harrington $\mathrm{KJ}$ et al. Guidelines for preclinical and early phase clinical assessment of novel radiosensitisers. Br J Cancer 2011;105(5):628-39.

[13] Sharma RA et al. Clinical development of new drug-radiotherapy combinations. Nat Rev Clin Oncol 2016;13(10):627-42.

[14] Karnitz LM, Zou L. Molecular pathways: targeting ATR in cancer therapy. Clin Cancer Res 2015;21(21):4780-5. 